\title{
Políticas culturales locales: con la mirada puesta en el futuro
}

\section{Jordi Font i Cardona}

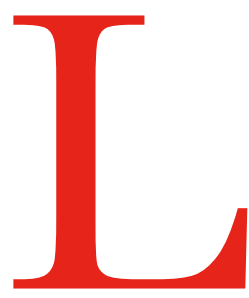

as políticas culturales no escapan a la transición ciega en la que el mundo se halla inmerso. No sabemos aún con precisión cuáles van a ser los nuevos paisajes que la mutación tecnológica en curso nos va a deparar y ello nos impide una anticipación lo bastante fundamentada, así como el diseño de proyectos transformadores y solventes que restablezcan el horizonte, levanten el ánimo y pongan fin a los miedos que dan falsas seguridades populistas.

Una cosa sabemos con certeza: que no solo se trata de una gran mutación estructural, sino también de una mutación cultural sin precedentes, de dimensiones colosales. Cosa que aumenta nuestra desazón al hacernos conscientes del diferencial enorme que existe entre el reto que se nos viene encima y el estado aún precario en que se hallan las políticas culturales. Una desazón saludable, porque nos empuja a superar limitaciones y a crear las condiciones para un estadio de mayor rigor y reconocimiento para las políticas culturales y de mayor centralidad para la cultura en las políticas de gobierno.

A falta de mayores luces, a continuación, ensayo dos aproximaciones:
A. Mediante nueve parámetros que tratan de caracterizar la dimensión cultural de los grandes cambios estructurales en curso.

B. Mediante trece acentos referidos a algunos aspectos de las políticas culturales locales que, a mi modo de ver, encierran claves importantes para la progresión de estas.

\section{A. Nueve parámetros:}

I. La red, el fundamento básico de la mutación en curso, tuvo un primer efecto extraordinario: el acceso universal e inmediato a casi todo, a la información, al conocimiento acumulado, a buena parte de los bienes culturales y artísticos. Ello constituye una herramienta de un potencial infinito para la realización de uno de los móviles fundacionales de las políticas culturales, eso que vinimos en llamar «democratización de la cultura».

II. Pero la red ha tenido también un segundo efecto de mayores consecuencias: el fin de la hegemonía unidireccional arriba-abajo, para dar lugar a la interacción abajo-arriba y a la interacción horizontal, con el consiguiente potencial 
de empoderamiento ciudadano - o, más técnicamente, de subsidiariedad social o, en lenguaje de hace algunos años, de autogestión - y, pues, con nuevas e ilimitadas posibilidades para el segundo móvil fundacional de las políticas culturales, lo que llevamos tiempo propugnando como «democracia cultural». Ha sido este, en principio, un golpe certero al Big Brother, a la distopía de un mundo determinado por un poder en la cima, con los medios unidireccionales a su servicio, capaz de controlar toda la información y, por consiguiente, de manejarnos a su antojo. Lo ha subvertido de lleno la capacidad de cuestionamiento y de información alternativa que supone la red, el feed-back multidireccional. Esto comporta también un hecho nuevo para la cultura local: la fácil irrupción global de realidades culturales locales hasta ahora invisibles, al punto de ganarse, en algunos casos - y particularmente en el campo de la música-, una demanda global insospechada, un segmento de público sin fronteras que, por pequeño que sea, resulta multitudinario.

III. También hay nuevos poderes nacidos a partir de la red que parecen querer recuperar el terreno desde arriba mediante los algoritmos que escrutan nuestros movimientos, nos diagnostican y se disponen a poseernos tirando de nuestras emociones, de nuestros reflejos básicos y de nuestro cerebro reptil. Frente a ello, es necesaria una ciudadanía en guardia, menos crédula, capaz de proteger lo que nos hace humanos: nuestra corteza frontal, nuestra capacidad de calcular y discriminar, de tomar decisiones ajenas a nuestras propias inercias, de plantearnos criterios morales y de ejercer la libertad. Es decir, nos hace falta más capacidad crítica, más cultura.

IV. La educación, en buena parte, resulta hoy impotente ante los innumerables y caóticos influjos «educadores» que reciben los alumnos desde todos los ángulos. Se echa en falta una acción educadora de mayor envergadura, que no descanse solo en las espaldas de la escuela y el instituto, sino en una acción mancomunada de todos los agentes públicos y sociales en juego. La expresión «ciudad educadora», en boca del mundo educativo, sintetiza la reivindicación de esa corresponsabilidad y cooperación para una ciudadanía crítica, responsable, creativa y con capacidad de iniciativa. Ello viene a coincidir con la impotencia de las políticas culturales para romper sus techos endémicos y llegar al conjunto de la ciudadanía, para lo cual el sistema educativo, con su implantación e incidencia universales, puede constituir una vía valiosísima de proyección social. Hace falta, sin duda, el im- pulso público de un programa de actuación que integre políticas educativas, culturales, sociales y mediáticas, así como las familias y los agentes sociales dispuestos a cooperar en ello.

V. La robotización, junto a un incremento geométrico de la productividad y de las rentas, nos augura la disminución del trabajo humano y la necesidad de avanzar hacia una nueva organización de este y hacia a nuevos modelos de redistribución de la riqueza. En cualquier caso, se avecina una nueva relación de los humanos con el trabajo, con un gran incremento del tiempo libre y, pues, con unas posibilidades inéditas para el trabajo desinteresado, solidario y vocacional, así como para la cultura y las artes. Un salto cultural sin precedentes desde que fuimos expulsados del Edén y condenados a ganarnos el pan con el sudor de nuestra frente, pasando por el largo trecho en que, haciendo de la necesidad virtud, hemos disfrazado esa condena, para la mayoría tan alienante como nos la pintó Charles Chaplin - Tiempos modernos - como fuente de dignidad y realización personal. Tal es el síndrome de Estocolmo que algunos agoreros, ante la anunciada caída del trabajo asalariado, temen por una deriva errante de los humanos desocupados. Va a ser la más grande y emancipadora revolución cultural.

VI. Las grandes migraciones van a ser una constante en el mundo globalizado, por lo menos mientras subsistan los desequilibrios económicos, sociales y políticos. Hay que asumir, pues, un incremento del grado de diversidad cultural en nuestras sociedades y prepararlas para asumirlo en términos de enriquecimiento cultural y el reconocimiento. Pero no solo esto, sino que debe de ir acompañado de un designio irrenunciable de integración, de fusión en una identidad compartida de futuro, todavía en construcción. Un grado suficiente de cohesión social y cultural es condición de la vida en común y del consenso que fundamenta la democracia. De ahí el creciente rechazo tanto del asimilacionismo, que menosprecia la diferencia y puede generar dinámicas de contra-sociedad, como de la multiculturalidad, que, en nombre de «la igualdad en la diferencia», precipita la cristalización de comunidades estancas y potencialmente en conflicto. Frente a ambos, hay un acuerdo creciente en torno a lo que denominamos interculturalidad, es decir, a la secuencia reconocimiento-interacción-fusión. Un reto social y cultural de primerísima magnitud.

VII. Los Estados-nación son un instrumento cada vez más disfuncional. Nos hacen falta, con urgencia, gobiernos 
continentales con capacidad de incidencia global. Y adquieren una creciente vigencia los gobiernos de proximidad, especialmente los gobiernos locales, capaces de interactuar con la gente concreta, con sus necesidades y sus deseos, diseñando soluciones a medida capaces también de sumar energías públicas y sociales. El acceso a la intemperie global ha actualizado como nunca la necesidad de lo local y de las referencias distintivas, identitarias. Se pone en valor el roce, la vivencia compartida, la vida cultural comunitaria, que es el lugar fundamental de la ciudadanía y el terreno donde cultivar los derechos culturales. Incluso lo global anda a la caza de contenidos arraigados al pálpito de las gentes, que sean «auténticos». Dice Manolo Castells

cuanto más abstracto se hace el poder de los flujos globales de capital, tecnología e información, más concretamente se afirma la experiencia compartida en el territorio, en la historia, en la lengua, en la religión, en la etnia. El poder de la identidad no desaparece sino que se refuerza. El mito universalista de los racionalismos liberal y marxista ha sido desmentido por la experiencia histórica. La cuestión que se plantea entonces en el mundo de las identidades, es el de las condiciones de su comunicación y de su proyección en un futuro compartido. Pero ello exige un reconocimiento previo.

De ahí la importancia creciente del marco local y, en él, de la cultura.

VIII. Por otro lado, el Estado del Bienestar, que es una cota política y moral irrenunciable, viene tocando techo y es preciso sumar fuerzas y generar sinergias en respuesta a las necesidades crecientes que plantea por cuenta de las diversas administraciones y con el concurso de la iniciativa privada y de la iniciativa social. Es lo que llamamos Estado Relacional, que es el Estado del Bienestar reforzado con la concertación público/privado y con la concertación público/social, siempre bajo criterio y dirección públicos, haciendo falta profundizar en la transparencia de esta concertación. Un aspecto fundamental de la concertación público/privado es la competitividad global de las industrias culturales, de manera que sean capaces de ganar un lugar para las culturas nacionales y locales.

IX. La política cultural ha avanzado mucho, aunque choca con una pared invisible: la resistencia, a veces incons- ciente, del poder político y económico para darle el lugar autónomo que le corresponde. Ello solo va a ser posible cuando las políticas culturales alcancen un grado suficiente de sistematización del conocimiento acumulado, de asentamiento de criterios básicos, de establecimiento de estándares, de instauración de formas de medición y evaluación homologadas. Solo así las políticas culturales van a ganarse una legitimidad suficiente. A falta de ello, subyacen las inercias de la relación «señorial» del poder para con la cultura, reducida a arca de los hechizos y a saco de los oropeles. Son los ancestrales reflejos condicionados del guerrero para con el brujo. Otra batalla fundamental al respecto es la del reconocimiento de los derechos culturales de la ciudadanía, ganando un lugar preciso para la cultura dentro del contrato social. Es el camino que está tratando de impulsar la Agenda 21 de la Cultura.

\section{B. Trece acentos}

(Señalados a partir del trabajo sobre el "Espacio Cultural Metropolitano”, que elaboré en 2017-2018, por encargo del Institut de Cultura de Barcelona (ICUB), en el marco de los encuentros metropolitanos de concejales de cultura)

1. El libre acceso a casi todo y la consiguiente sobreabundancia de información, cierta o falsa, da lugar al síndrome de «la aguja en el pajar». Es decir, precisa de una capacidad de discernimiento cualitativo de la que la ciudadanía no siempre dispone. Umberto Eco contaba, en un artículo, que, un día, alojado ya en la ciudad escandinava donde tenía que dar una conferencia al día siguiente, advirtió, para su espanto, que su texto había quedado olvidado en casa. A continuación, cantaba las maravillas de internet que, en un par de horas, le había permitido rehacer por completo su texto, citas incluidas. Sin embargo, en un lacónico punto y aparte, advertía: «Pero ojo: yo soy Umberto Eco». Es decir, que no todo el mundo estaba en condiciones de realizar semejante hazaña. Hacía falta gozar de un alto grado de capacidad crítica y discriminadora. De ahí, la importancia anticipadora de lo que un día vinimos a llamar «bibliotecas de nueva generación», en las que no se trataba tan solo de poner a mano de la comunidad local los diversos soportes de la información, el conocimiento y las artes, sino también de introducir una nueva función: lo que denominábamos «guardia urbana de la red» o guía calificada y orientadora, en conexión con expertos contrastados para cada materia, con la misión de facilitar al ciudadano/a el hallazgo de su aguja en el pajar. 
Un servicio a demanda sobre todo de sujetos colectivos de la comunidad - escuelas e institutos, profesionales, empresas, entidades sociales, grupos de interés...- y permanentemente reciclado a partir de estos. Desarrollar al máximo esta función es la misión de futuro de ese equipamiento que denominamos biblioteca y que está llamado a ser, para la ciudadanía, un centro de acceso calificado a la información, proveedor de planos y brújulas para una navegación certera, sin derivas, en el océano proceloso de la red.

2. En el terreno de la difusión de las artes es donde arrastramos más frustraciones. No hay forma de romper los techos de público. Para ello, es imprescindible superar las inercias que tienden a relegar la difusión a los públicos ilustrados clásicos, con un sesgo social y generacional clamoroso, para aprestarse a sintonizar con todos los segmentos sociales, a encarar la diversidad de públicos existentes, asumiendo que el cultivo de la sensibilidad estética no pasa solo por el saber y las artes más homologados, sino que abarca los más vastos territorios de la experiencia humana, cada vez más diversa. Hay que ampliar la mirada cultural de las políticas culturales, para poder ampliar, así, la mirada cultural de cada segmento ciudadano, sus intereses y sus potencialidades. No público, sino públicos, en plural. Son especialmente interesantes, en este sentido, algunos ensayos de segmentación de los auditores/as y de la oferta realizados en algunos municipios, ampliando el abanico y las modalidades de lo programable y, sobre todo, con un tratamiento sistemático y acumulativo de cada segmento - el «carnet cultural» es un instrumento importante al respecto-, propiciando la ampliación progresiva de sus intereses. El municipio de Viladecans es un caso paradigmático al respecto.

3. El eje cultura-educación aparece como algo fundamental para la ampliación de los públicos. En primer lugar, porque la educación estética de la población escolar es la formación de los públicos del mañana. Y, en segundo lugar, porque la implantación universal del sistema educativo resulta un canal óptimo para relacionar las políticas culturales con la inmensa mayoría de la población. La puesta en común y la cooperación estratégica de los departamentos de cultura y educación, siendo una necesidad sentida desde ambos sectores, entraña sin embargo importantes dificultades, derivadas de las pesadas inercias de la estructura educativa y del sesgo elitista que pesa aún sobre muchas políticas culturales.

Una vieja asignatura pendiente, en este eje, es la alfabetización artística dentro de la educación obligatoria, tanto primaria como secundaria, de la cual se desprende la persistencia inaceptable de un nivel inadmisible de analfabetismo artístico, con el hándicap que ello supone para la capacidad expresiva y creativa de la ciudadanía y para su capacidad de disfrute de los bienes artísticos. Esta es una de las causas fundamentales del techo con el que chocan tantas buenas intenciones de difusión artística. Se impone reformular los currículos docentes, acabar con el tira y afloja gremial desde las diversas materias y avanzar hacia una definición de contenidos más seria, al servicio de la formación integral de la persona. La educación de la sensibilidad y, pues, la alfabetización artística, es clave en este sentido. Una experiencia interesante al respecto es la del ayuntamiento de El Prat, que consiguió, del gobierno catalán, la implantación de escuelas piloto con proyectos pedagógicos innovadores y equipos docentes a la medida que incorporan a su currículo, en horario escolar, la música o el teatro o la danza, no solo como materia sino como opción pedagógica básica del centro, con una función trasversal que se revela catalizadora de capacidades inteligentes no siempre movilizadas. Todo ello viene enmarcado en un programa conjunto de las áreas municipales de Cultura y Educación, con la implicación de familias y de entidades comunitarias diversas.

4. En relación con el tratamiento de los públicos jóvenes, además de la acción sobre la educación secundaria, tienen especial interés los incipientes circuitos de las artes emergentes, con frecuencia inter-fronterizas o de fusión. A medio camino de la profesionalización, se trata de creaciones que concitan una clara identificación generacional y que suelen ofrecerse en régimen de Circuito $\mathrm{B}$ a precios especialmente asequibles y en espacios no habituales - universidades, centros culturales, espacios informales, hasta viviendas particulares en el más pequeño formato, etcétera- El apoyo al arte emergente, a la sensibilidad joven, se concreta en las casas de cultura o centros cívicos y, particularmente, en las llamadas «fábricas de creación», cuyas intenciones primeras, no siempre conseguidas, contemplaban la interacción comunitaria, generadora de beneficios sociales y fuente también de inspiración artística. Al respecto, son importantes, aunque poco desarrolladas, las políticas de promoción, mediante el entronque con los circuitos intermunicipales de difusión y los promotores privados. Espai Brossa de Barcelona, de la mano de Ferran Mádico, a partir de las experiencias parciales existentes, se viene planteado poner en pie un circuito emergente metropolitano, en conexión con los ayuntamientos de la conurbación barcelonesa. Un yacimiento importante de nue- 


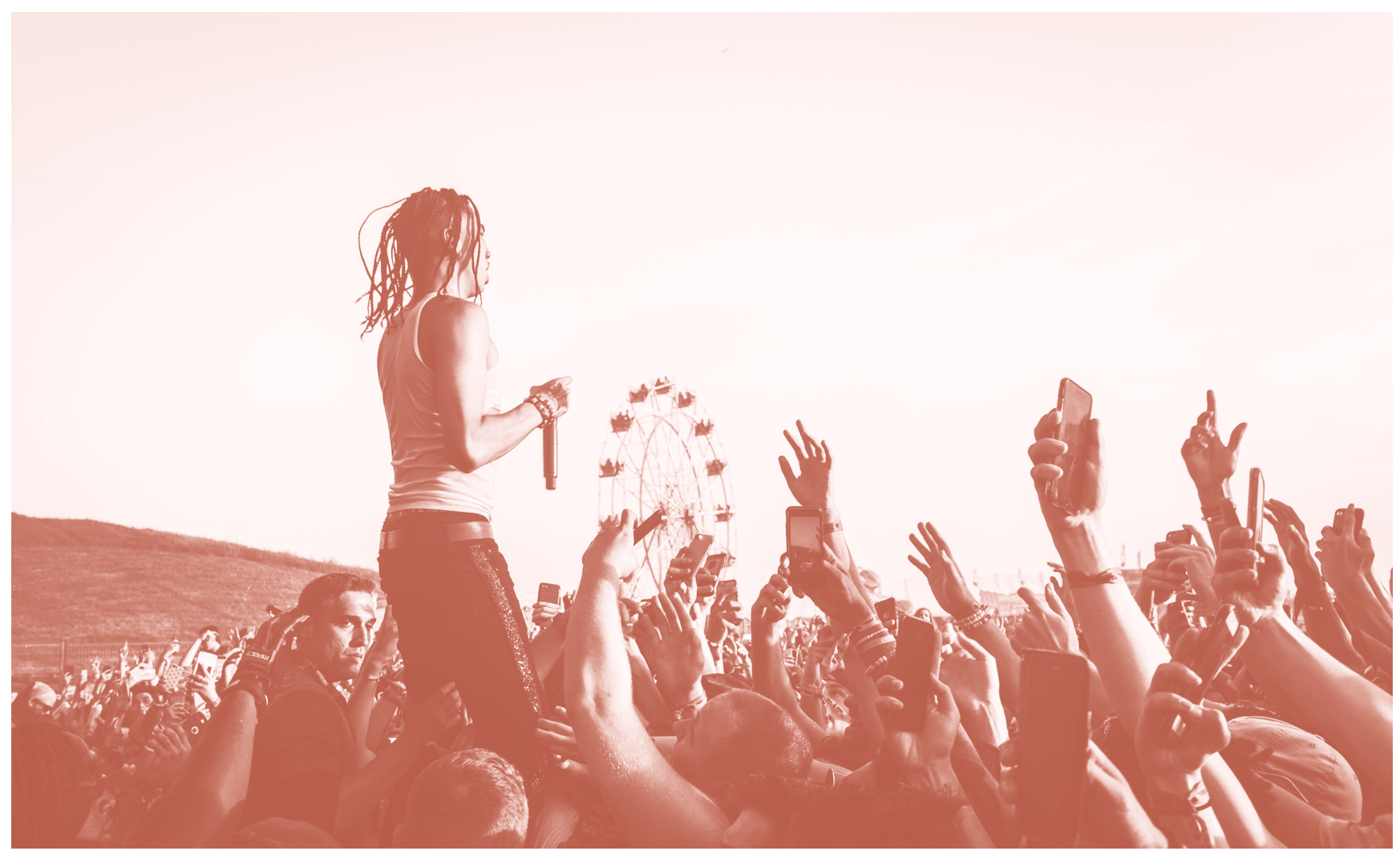

vos valores, programables en condiciones muy asequibles y todavía muy poco explotado por las políticas locales, es la educación artística superior, con sus posgrados especializados y sus actuales o potenciales «jóvenes compañías» y «jóvenes orquestas».

5. Hay un sujeto artístico que tiende a hacerse presente de manera creciente en algunos campos de actividad no artísticos, entre los cuales la vida comunitaria. Se trata de la proliferación de graduados de las escuelas artísticas superiores que la demanda no puede absorber con continuidad, de modo que dan lugar a un considerable excedente de artistas muy bien preparados que, como mucho, van a obtener una profesionalización artística intermitente y van a estar disponibles, pues, para ensayar la aplicación de sus conocimientos y habilidades a otros campos donde pueden ser útiles: particularmente, a los campos de la educación, la vida comunitaria, la salud, la dinámica de grupos, etcétera. No son pocos los casos que confirman el gran valor social que adquieren las artes aplicadas a las dinámicas comunitarias (tratamiento de toda clase de disfunciones sociales, reconocimiento de la diferencia, dinámicas integradoras...). Hay que señalar dos plataformas de referencia obligada al respecto: las "Jornadas de Inclusión Social y Artes Escénicas" del Ministerio Cultura (INAEM) y el Observatorio de Artes Escénicas Aplicadas del Institut del Teatre (Barcelona).

6. Un modelo prometedor y poco explotado es la implantación local de algún grupo artístico, encargado de desarrollar funciones docentes en escuelas e institutos y, a la vez, funciones de animación cultural comunitaria y hasta de programación de la difusión. Es lo que, frente a los habituales círculos viciosos de la difusión poco lograda, vinimos en llamar «triángulo virtuoso». Tres vértices lo componen: creación arraigada, educación, difusión. Son especialmente interesantes al respecto el conocido caso del TPK (Taller de Artes Plásticas de Pubilla Casas en l'Hospitalet), la Factoria SI (Cornellà). Y, particularmente, ese caso pionero de los ochenta: el municipio de Vila-seca, con su Cor Sant Esteve. Tratándose de un municipio pequeño, la dinámica musical 
emprendida registró unos efectos espectaculares tanto en la educación como sobre las dinámicas familiares y comunitarias. De tener solo un coro y ser un municipio desestructurado, con una inmigración que había cuadruplicado su población en tres años, pasó, con el tiempo, a disponer de un conservatorio, un gran auditorio, cuatro orquestas, siete coros, dos conjuntos de guitarras, dos conjuntos de viento, un cuarteto de cuerda...; mientras muchos de sus músicos están tocando hoy en orquestas de todas partes o dando clases en conservatorios y escuelas de música. Un caso realmente impresionante.

7. Las asociaciones de usuarios de algunos servicios - público de un teatro, madres y padres de centro educativo implicados en la programación cultural, asiduos del taller de fotografía de la casa de cultura, etc.- son embriones importantes a partir de los cuales generar subsidiariedad social, cogestión, autogestión, empoderamiento... Delegando en ellos determinadas funciones gestoras, capacidad de reformulación del servicio a la medida de las necesidades y expectativas por ellos vividas. Esto, manteniendo siempre desde la administración una tensión saludable entre la parte y el todo, entre la ciudadanía organizada y el conjunto de la ciudadanía que ha de ser siempre el destinatario.

8. Los Centros de Interpretación del Patrimonio (CIP) son un invento especialmente interesante en el campo de la difusión del patrimonio, con resultados sobradamente contrastados. Un espacio, con una exposición permanente, que ofrece una visión integral del tema (sea del patrimonio cultural del municipio sea de una rama de actividad humana característica de la zona...) y que da pie a uno o a más circuitos patrimoniales en el municipio y su entorno. Comporta utilidades fundamentales para la educación y para la identificación local, y constituye un destino habitual para públicos organizados y para el turismo cultural con la generación, muchas veces, de importantes sinergias de carácter económico.

9. La obtención de alguna centralidad general es un objetivo importante para todo municipio. Es aquello que lo sitúa en el mapa y lo pone en valor hacia afuera. Y que, por el efecto espejo, lo pone también en valor hacia adentro, generando autorreconocimiento entre la ciudadanía. Se trata de ser «la meca» de algo, la capital de alguna actividad, el centro de alguna especialización, con la consiguiente atracción sobre los seguidores de la misma, más allá del munici- pio, cosa que erige a este en una referencia regional o internacional. Con mucha frecuencia la cultura o la naturaleza son motivo de centralidades que mueven a mucha gente. Es el caso de tantos festivales de referencia sectorial: Festival Internacional de Payasos (Cornellà); Festival Altaveu de Canción (Sant Boi); Festival de Magia "Li Chang" (Badalona), etc., o de los fondos especializados dentro de las bibliotecas de lectura pública: fondo Mendiluce (Poble Nou), fondos de escritores diversos (Gràcia, Sant Martí de Provençals...), fondo de Novela Negra Internacional (L'Hospitalet), etcétera. Destacan, además, algunas singularidades en patrimonio cultural o natural (minas de sal de Cardona, minas prehistóricas de Gavà...).

10. Es importante influir, desde parámetros culturales, en las políticas municipales que inciden en el tratamiento de la inmigración, de manera que redunden en la deseable cohesión social y cultural.

-Garantizar un asentamiento adecuado, sin concentraciones que conduzcan al gueto urbanístico y cultural.

-Impulsar políticas educativas que eviten la concentración en determinados centros y que, para ello, impliquen a todo el sistema educativo, escuela concertada incluida.

-Desarrollar una ingeniería social a nivel de vecindario, de la mano de los diversos agentes sociales, para que la diferencia de hábitos no genere conflicto, para que los derechos humanos, especialmente los de la mujer y la infancia sean garantizados, etcétera.

En términos de modelo general, como ya hemos comentado, está cada día más claro el rechazo tanto el asimilacionismo - que conlleva graves hándicaps personales y que puede generar dinámicas de contra-sociedad y hasta de respuesta violenta - como el rechazo a la multiculturalidad estanca - que trae segregación y fractura social-, para propiciar, en su lugar, políticas de interculturalidad, es decir, de reconocimiento cultural y, a la vez, de interacción y fusión, de identidad compartida de futuro. Ello tiene mucho que ver con la cultura política como generadora de proyecto colectivo y, con él, de identidad de futuro.

Hay multitud de buenas prácticas referidas a la inmigración, a veces en los lugares más críticos. Es el caso de Santa Coloma de Gramenet: 110 nacionalidades, con una densidad semejante a la de Calcuta. En ese Babel, ha tomado cuerpo, de la mano de la Biblioteca del barrio del Fondo y del Restaurante Llerona (la estrella Michelin más barata de España), el Programa "Cuines del món” (Cocinas del mundo), mediante el cual las diversas cocinas familiares se erigen 
en vía de contacto, de mutuo reconocimiento, de intercomunicación gratificante y hasta de experimentación y fusión culinaria. Reconocerse e interactuar es la clave. En el fondo, más allá de demagogias populistas, late, en la gente, un deseo general de encuentro, que prende en cuanto se le da ocasión.

11. Deontología. La relación de los servicios públicos con la iniciativa ciudadana requiere hilar fino. Demanda una distinción nítida entre administración, ciudadanía y organizaciones sociales, frente a instrumentalizaciones y suplantaciones:

-La administración debe evitar cualquier deriva hacia la «correa de transmisión» partidista o de cualquier interés particular, limitándose a garantizar las condiciones públicas necesarias para la democratización cultural y para la democracia cultural. Y, particularmente, debe ser garantía contra dos suplantaciones clásicas:

-La suplantación del servicio público por el gestor cultural que se arroga el estatus del artista (subjetivo, arbitrario) y convierte el centro cultural en su lienzo. El gestor ha de ser riguroso consigo mismo y ser garante del servicio público universal. Su función principal es la de comadrona comunitaria, atando cabos, generando interacciones, ayudando a nacer proyectos.

-La suplantación de la ciudadanía por las organizaciones sociales. Sin perjuicio de avanzar hacia todas las formas de subsidiariedad social posibles, nunca debe tomarse la parte por el todo. Hay que impulsar y orientar la iniciativa social al servició del conjunto de la ciudadanía, evitando «el síndrome del candado» (en referencia a las entidades que, a veces inconscientemente, se apropian del equipamiento público en lugar de fecundarlo y acercarlo a la ciudadanía).

12. En el ámbito local, el nivel supramunicipal es clave para las políticas culturales municipales. En particular, las diputaciones. Su competencia es el apoyo a los ayuntamientos, un apoyo que puede quedar en la clásica repartidora de subvenciones o que puede ir mucho más allá: la gestión en red de los servicios culturales municipales (o de sistemas, si incluyen planes e inversión para los correspondientes equipamientos). Ello no sólo suma capacidades sino que las multiplica, mediante:

-el establecimiento de economías de escala, como es el caso de las compras y contrataciones conjuntas que disminuyen costes.

-la generación de sinergias, que permiten un salto cualitativo, como es el caso, por ejemplo, del préstamo inter- bibliotecario o de la puesta en valor de la cuota de mercado conjunta para incidir en la producción de espectáculos.

En el caso de la Diputación de Barcelona, pionera de este modelo desde 1983, dio lugar, a diversas redes y circuitos más o menos formalizados:

-La red de lectura pública, con las bibliotecas de nueva generación y sus estrategias y logísticas compartidas como «centros locales de acceso cualitativo a la información y al conocimiento».

-Las programaciones municipales de música, teatro y danza, con la organización de circuitos conjuntos, con sus giras y estrategias compartidas (políticas de comunicación, promoción de artistas emergentes...).

-La red de museos y de CIPs (Centros de Interpretación del Patrimonio) y su concertación con las agencias de públicos organizados (escuelas, tercera edad, turismo cultural...).

-La red de archivos municipales y su relación con el memorialismo local (revista "Plecs d'història local").

-La producción y circulación de exposiciones itinerantes, de artes visuales o temáticas.

-Etcétera.

13. Respecto a la sistematización y legitimación de las políticas culturales y a la defensa de su autonomía, urge avanzar hacia:

-La puesta en común de los másteres existentes y el compromiso de la universidad en la fijación y el desarrollo del conocimiento acumulado, particularmente en el campo de la economía de la cultura y de la evaluación de programas y rentabilidades sociales.

-El establecimiento de instancias prescriptoras (observatorios, consejos de las artes...), que fijen criterios básicos y estándares de servicios, que demanden planes de equipamientos en el territorio y elaboren sistemas de evaluación, que hagan inexcusable la coordinación entre las administraciones, etcétera.

-La fijación de marcos competenciales que establezcan las responsabilidades precisas de cada administración, dotándolas de los consiguientes recursos económicos y acabando, de una vez, con el escándalo de una administración local que presta todos los servicios culturales de proximidad sin que estos figuren entre sus competencias - con la única excepción del sistema de lectura pública - y, pues, sin que los correspondientes recursos figuren entre las dotaciones económicas que se le asignan. 